\title{
Severe Ketoacidosis as the First Clinical Manifestation of Type 1 Diabetes Mellitus Secondary to Immune Checkpoint Inhibitors
}

\author{
Alejandro Olivares-Hernández ${ }^{1,2}$ Roberto A. Escala-Cornejo ${ }^{2,3}$ Araceli R. García-Domínguez ${ }^{1,2}$ \\ Juan J. Cruz-Hernández 1,2,4 \\ 1Department of Medical Oncology, University Hospital of \\ Salamanca, Salamanca, Spain \\ 2Department of Research, Institute for Research Cancer of \\ Salamanca (IBSAL), Salamanca, Spain \\ ${ }^{3}$ Department of Medical Oncology, Healthcare Complex of Ávila, \\ Ávila, Spain \\ ${ }^{4}$ Faculty of Medicine, Edificio de Rectorado, University of \\ Salamanca, Salamanca, Spain

\begin{abstract}
Address for correspondence Alejandro Olivares-Hernández, MD, Department of Medical Oncology, University Hospital of Salamanca, Paseo de San Vicente, 58-182 CP 37007, Salamanca, Spain (e-mail: aolivares@saludcastillayleon.es).
\end{abstract}

Asian J Oncol 2020;6:94-96

\section{Abstract}

Keywords

- C-peptide

- immunotherapy

- ketoacidosis
Introduction Immunotherapy represents one of the fundamental points on the oncological treatments. The increasingly frequent use of these treatments has allowed us to observe various side effects in up to 10 to $20 \%$ of patients and endocrine side effects are one of the most commonly described. We report a case of diabetic ketoacidosis in a 46-year-old male patient as debut of type- 1 diabetes mellitus secondary to treatment with nivolumab.

Case Report The patient who went to the emergency department due to abdominal pain associated with vomiting 48 hours previously. Diagnosed 4 years ago of clear cell renal carcinoma stage IV, due to pulmonary metastatic involvement, the patient was under treatment with nivolumab. Urgent blood and urine tests were performed in the urgency evaluation; the patient was diagnosis of severe diabetic ketoacidosis. Pancreatic endocrine complications are observed in 0.5 to $5 \%$ of the patients with immunotherapy. Among the adverse effects described are alterations in baseline fasting glycaemia and the possible development of type- 1 diabetes. These molecules increase the activity of T-cells, amplify the cellular immune activity with the consequent increased immune response, which can lead to a destruction of the pancreatic $\beta$-cells. Strict endocrine control is necessary during immunotherapy treatment; however, there are no clear indications for the monitoring of pancreatic reserve levels or glycemic control. For these reasons, we propose the need for closer and regular monitoring of C-peptide and HbA1c (glycosylated hemoglobin) to prevent the development of the diabetes and their complications.

\section{Introduction}

Oncological treatments are often based on immunotherapy. Immune control points (or "checkpoints") include cell surface molecules that act as endogenous regulators of the immune response and, therefore, are perfect therapeutic targets. ${ }^{1}$ One of the best-known checkpoints is the programmed cell death protein 1 receptor (PD-L1 or programmed death 1 ) that is found on the surface of immune cells.,3 When PD-L1 binds to its ligand (PD-L1 and PD-L2), the activation pathways of the immune cell are inhibited. Using various monoclonal antibodies, activation of the immune system can take place, acting at the receptor or ligand level, thereby enhancing antitumor activity. ${ }^{4}$ published online April 21, 2020
DOI https://doi.org/ 10.1055/s-0040-1710147 ISSN 2454-6798.
License terms

() (1) $\ominus \circledast$ 
The increasingly frequent use of these treatments has allowed us to observe various side effects, which occur in up to 10 to $20 \%$ of patients. ${ }^{5,6}$ Endocrine side effects are the most common type described for these drugs ${ }^{7}$; between 5 and $10 \%$ of patients develop an endocrinological disorder. In this article, we report a case of diabetic ketoacidosis prior to a diagnosis of type-1 diabetes mellitus, secondary to treatment with nivolumab.

\section{Case Report}

A 46-year-old male patient who presented with dyslipidemia as his only personal history (with no family history of type-1 diabetes mellitus) went to the emergency department due to abdominal pain associated with vomiting and nausea 48 hours previously. On physical examination, no sign of alarm was observed, except for slight dehydration of the skin and mucous membranes. Likewise, there were no signs of insulin resistance such as acanthosis nigricans, weight gain, or manifestations of metabolic syndrome. The patient's weight at the time of the emergency visit was $65 \mathrm{~kg}$ (height, $181 \mathrm{~cm}$; body mass index [BMI], $19.84 \mathrm{~kg} / \mathrm{m}^{2}$ ).

Four years previously, the patient had been diagnosed with stage-IV clear cell renal carcinoma with bilateral pulmonary metastatic involvement. This was treated with right radical nephrectomy and sunitinib, maintained for 24 months, until a reassessment. Computerized tomography (CT) showed a progression of the pulmonary and hepatic lesions, prompting treatment with nivolumab, and resulting in a complete response of the pulmonary lesions and partial liver damage.

Urgent blood and urine tests were performed as part of our evaluation ( $\mathbf{- T a b l e ~} \mathbf{1}$ ) in which a picture of diabetic ketoacidosis could be seen. The patient's previous blood glucose levels had never been higher than $110 \mathrm{mg} / \mathrm{dL}(6.10 \mathrm{mmol} / \mathrm{L})$ at any time, and he had not reported hyperglycemia symptoms

Table 1 Urgent blood and urine test

\begin{tabular}{|l|l|l|}
\hline Determination & Results & Laboratory range \\
\hline Glucose & $32.03(\mathrm{mmol} / \mathrm{L})$ & $3.89-5.55(\mathrm{mmol} / \mathrm{L})$ \\
\hline Creatinine & $0.21(\mathrm{mmol} / \mathrm{L})$ & $0.06-0.11(\mathrm{mmol} / \mathrm{L})$ \\
\hline FG $($ CKD-EPI) & $\begin{array}{l}32(\mathrm{~mL} / \mathrm{min} / \\
\left.1.73 \mathrm{~m}^{2}\right)\end{array}$ & $\geq 90\left(\mathrm{~mL} / \mathrm{min} / 1,73 \mathrm{~m}^{2}\right)$ \\
\hline GAP anion plasma & $38.23(\mathrm{mmol} / \mathrm{L})$ & $8,00-16.00(\mathrm{mmol} / \mathrm{L})$ \\
\hline $\mathrm{pH}$ & 7.11 & $7.35-7.45$ \\
\hline $\mathrm{pCO}{ }_{2}$ & $22.00(\mathrm{~mm} \mathrm{Hg})$ & $35-45(\mathrm{~mm} \mathrm{Hg})$ \\
& $2.93(\mathrm{kPa})$ & $4.67-6(\mathrm{kPa})$ \\
\hline Bicarbonate & $7.00(\mathrm{mmol} / \mathrm{L})$ & $\begin{array}{l}26.00-32-00 \\
(\mathrm{mmol} / \mathrm{L})\end{array}$ \\
\hline $\begin{array}{l}\text { GAD65 } \\
\text { autoantibodies }\end{array}$ & $1.6(\mathrm{UI} / \mathrm{mL})$ & $0.0-5.0(\mathrm{UI} / \mathrm{mL})$ \\
\hline IAA & $1.3(\mathrm{UI} / \mathrm{mL})$ & $0.0-0.4(\mathrm{UI} / \mathrm{mL})$ \\
\hline IA-2 autoantibodies & $3.6(\mathrm{Ul} / \mathrm{mL})$ & $0.0-0.8(\mathrm{UI} / \mathrm{mL})$ \\
\hline Ketone bodies urine & $>3.0(\mathrm{mmol} / \mathrm{L})$ & $0.0-0.5(\mathrm{mmol} / \mathrm{L})$ \\
\hline Glucose urine & $>55.51(\mathrm{mmol} / \mathrm{L})$ & $0.0-0.83(\mathrm{mmol} / \mathrm{L})$ \\
\hline
\end{tabular}

Abbreviations: CKD-EPI, chronic kidney disease epidemiology collaboration; FG, glomerular filtration; GAD65, glutamic acid decarboxylase; IA-2, islet antigen-2; IAA, insulin autoantibodies. such as polydipsia, polyuria, or dyspnea. Treatment was started with bicarbonate, intravenous insulin, and fluid therapy in the medical oncology unit, with a good response (decrease in blood glucose levels and normalization of the $\mathrm{pH}$ and renal function values). During diabetic assessment, a glycosylated hemoglobin (HbA1C) of 9.4\% and a C-peptide of 0.182 (nmol/L) were observed.

The patient presented good clinical evolution during admission, with normalization of blood glucose levels and disappearance of symptoms, given this good evolution, it was decided to discharge with insulin treatment, 16 units of insulin degludec basal, and insulin action rapid as part in a corrective pattern based on preprandial blood glucose levels.

\section{Discussion}

Endocrine side effects with treatments based on immunotherapy are observed in 5 to $10 \%$ of patients and can be severe in many cases. ${ }^{8,9}$ Pancreatic endocrine complications are described in 0.5 to $5 \%$ of cases. Alterations in baseline fasting glycemia and the development of type- 1 diabetes are among the adverse effects described. ${ }^{10}$ These immunotherapies, when producing the inhibition of the pathways that lead to the arrest of T-cell activity, amplify the cellular immune activity, and the consequent increased immune response can lead to a destruction of the pancreatic $\beta$-cells. ${ }^{11,12}$ Diabetic ketoacidosis is a rare complication (in $\sim 0.1 \%$ of patients) described in treatments with anti-PD-1 molecules. In our patient, we observed extremely low levels of C-peptide, which reflects the scarce pancreatic reserve of the patient at the time of diagnosis, which aggravated the debut and, ultimately, required insulin treatment at discharge. The HbA1C figure presented by the patient, $9.4 \%$, correlated with a mean glycemia of $12.32(\mathrm{mmol} / \mathrm{L})$ in the 3 months prior to the analytical determination, demonstrating the rapid evolution of $\beta$-cell loss in the pancreas. The honeymoon period observed in young patients with a recent diagnosis of type-1 diabetes was not observed in our patients after discharge. The average time, described in the literature, from the administration of the first dose to the onset of symptoms is 14.6 weeks; however, in the case of our patient, it is 40 weeks. Likewise, the average dose of immunotherapy received in the literature for the appearance of symptoms is 5.3 doses, and in the case of our patient it has been 14 doses of nivolumab. The comments previously exposed, allows us to observe that in most cases the DMT1 develops in a short period of time, this does not happen in the case of our patient, which illustrates the need to follow-up beyond the average described in other cases reported.

In contrast to other endocrine complications, there is no clear established therapy for cases of type-1 diabetes mellitus secondary to treatment with immunotherapy. For example, in other side effects due to immunotherapy, treatment with corticosteroids is routine. However, in cases of type- 1 diabetes, corticosteroids are typically avoided because of the fear of increasing the existing hyperglycemia. Thus, these patients are treated similarly to idiopathic type-1 diabetes patients. ${ }^{13}$ 
Strict endocrine control is necessary during immuno-therapy treatment, as well as every 3 to 6 months after the immunotherapy has finished. It is recommended to monitor levels of basal glycemia, ${ }^{14}$ Thyroid stimulating hormone (TSH), free T4, basal cortisol, luteinizing hormone (LH), follicle-stimulating hormone (FSH), and testosterone in men. However, there are no clear indications for the monitoring of pancreatic reserve levels or glycemic control, even though these patients develop hyperglycemia in an accelerated manner. For these reasons, we propose the need for closer and regular monitoring of C-peptide and HbA1c, which might avoid diabetic complications or arrest the development of type- 1 diabetes mellitus. ${ }^{15}$

\section{Conclusion}

The appearance of endocrine side effects in the treatment based on immunotherapy, results in a significant number of complications, which can be in many cases of seriousness. The endocrine monitoring protocols in these patients have not been adapted to a pancreatic level. In accordance with the above, we propose the follow-up of these patients through the monitoring of the C-peptide and the HbA1c in every 2 months.

\section{Funding}

None.

\section{Conflict of Interest}

None declared.

\section{References}

1 Iwai Y, Hamanishi J, Chamoto K, Honjo T. Cancer immunotherapies targeting the PD-1 signaling pathway. J Biomed Sci 2017;24(1):26

2 Keir ME, Butte MJ, Freeman GJ, Sharpe AH. PD-1 and its ligands in tolerance and immunity. Annu Rev Immunol 2008;26:677-704

3 Patel SP, Kurzrock R. PD-L1 expression as a predictive biomarker in cancer immunotherapy. Mol Cancer Ther 2015;14(4):847-856
4 Kythreotou A, Siddique A, Mauri FA, Bower M, Pinato DJ. PD-L1. J Clin Pathol 2018;71(3):189-194

5 Sood A, Cole D, Abdollah F, et al. Endocrine, sexual function, and infertility side effects of immune checkpoint inhibitor therapy for genitourinary cancers. Curr Urol Rep 2018;19(9):68

6 Castinetti F, Albarel F, Archambeaud F, et al. Endocrine sideeffects of new anticancer therapies: overall monitoring and conclusions. Ann Endocrinol (Paris) 2018;79(5):591-595

7 Spain L, Diem S, Larkin J. Management of toxicities of immune checkpoint inhibitors. Cancer Treat Rev 2016;44:51-60

8 Iglesias P. Cancer immunotherapy-induced endocrinopathies: Clinical behavior and therapeutic approach. Eur J Intern Med 2018;47:6-13

9 Tzoulis P, Corbett RW, Ponnampalam S, et al. Nivolumabinduced fulminant diabetic ketoacidosis followed by thyroiditis. Endocrinol Diabetes Metab Case Rep 2018;2018:18-0111

10 Mellati M, Eaton KD, Brooks-Worrell BM, et al. Anti-PD-1 and anti-PDL-1 monoclonal antibodies causing type 1 diabetes. Diabetes Care 2015;38(9):e137-e138

11 Chae YK, Chiec L, Mohindra N, Gentzler R, Patel J, Giles F. A case of pembrolizumab-induced type- 1 diabetes mellitus and discussion of immune checkpoint inhibitor-induced type 1 diabetes. Cancer Immunol Immunother 2017;66(1):25-32

12 Lowe JR, Perry DJ, Salama AK, Mathews CE, Moss LG, Hanks BA. Genetic risk analysis of a patient with fulminant autoimmune type 1 diabetes mellitus secondary to combination ipilimumab and nivolumab immunotherapy. J Immunother Cancer 2016;4:89

13 Aleksova J, Lau PKH, Soldatos G, McArthur G. Glucocorticoids did not reverse type 1 diabetes mellitus secondary to pembrolizumab in a patient with metastatic melanoma. BMJ Case Rep 2016;2016:bcr2016217454

14 Okamoto M, Okamoto M, Gotoh K, et al. Fulminant type 1 diabetes mellitus with anti-programmed cell death-1 therapy. J Diabetes Investig 2016;7(6):915-918

15 Olivares-Hernández A, Escala-Cornejo RA, Figuero-Pérez L, et al. Determination of anti-pancreatic islet cell antibodies for the prevention of type 1 diabetes mellitus as an immune-related adverse event secondary to treatment with immune checkpoint inhibitors. Ann Oncol 2019;30(suppl 11) :xi23-xi24 